\title{
Template-Based Synthesis of Nanoporous Hydroxyapatite
}

\author{
E. Salimi, ${ }^{1}$ J. Javadpour, ${ }^{1}$ and M. Anbia ${ }^{2}$ \\ ${ }^{1}$ Faculty of Material Science and Engineering, Iran University of Science and Technology, Narmak, Tehran 16846, Iran \\ ${ }^{2}$ Research Laboratory of Nanoporous Materials, Faculty of Chemistry, Iran University of Science and Technology, Narmak, \\ Tehran 16846, Iran \\ Correspondence should be addressed to E. Salimi, small_salim2005@yahoo.com
}

Received 30 August 2012; Accepted 21 September 2012

Academic Editors: H. Maiwa and K. Yamashita

Copyright ( 2012 E. Salimi et al. This is an open access article distributed under the Creative Commons Attribution License, which permits unrestricted use, distribution, and reproduction in any medium, provided the original work is properly cited.

Hydroxyapatite (HAp) particles, a potential starting material for bone substitutes, with nanopores were synthesized in the presence of cetyltrimethylammonium bromide (CTAB) and P123 as cationic and nonionic surfactants as the structuring units. Effect of nonionic surfactant concentration on surface areas is also investigated. Based on $\mathrm{N}_{2}$ adsorption-desorption isotherms investigation, surface area increased up to $50 \mathrm{~m}^{2} / \mathrm{g}$ by using $\mathrm{P} 123$ and $147 \mathrm{~m}^{2} / \mathrm{g}$ by using CTAB as porosity agent. Pore structure remained even after the removal of surfactant and calcinations at $400^{\circ} \mathrm{C}$.

\section{Introduction}

Hydroxyapatite, $\mathrm{Ca}_{10}\left(\mathrm{PO}_{4}\right)_{6}(\mathrm{OH})_{2}$ (denoted as $\mathrm{HA}$ ), is a form of bioceramics material [1]. It is chemically similar to bones and hard tissues found in humans. It is biocompatible and can be rapidly integrated into the human body. Owing to its bioactive property, HA is widely used in medicine and dentistry as a material for metallic implant coatings, or for bone cavity fillings [2, 3]. In addition, HA can be used as drug delivery agent, such as for the delivery of antitumor agents and antibodies in the treatment of osteomyelitis: a bone infection that is often treated by excision of necrotic tissue and irrigation of the wound [4]. Potential use of HA as a protein delivery agent was also examined [5].

Porosity in a biomaterial implant allows for the possibility of growth of natural bone. In recent years, HA has also been used as an acidic catalyst for Friedel-Crafts alkylation and Knoevenagel reactions [6].

The synthesis of mesoporous materials can be achieved using a supramolecular templating technique. In $1992[7,8]$ a group of Mobil scientists successfully demonstrated that such a templating technique could be used to prepare siliconbased mesoporous materials. The cooperative self-assembling of inorganic silicates and cationic surfactants produces a mesophase structure, and the removal of the organic component produces well-organized porous structures.
Surfactant-templated mesoporous materials have some specific features such as high surface areas and high adsorption capacities including the uniformity and periodicity of tunable mesopores [9-11], which are widely applicable to adsorbents and catalytic supports [12-18].

However, it is difficult to synthesize nonsilica-based mesoporous oxides, especially calcium phosphate species, are preferentially crystallized in aqueous solutions and then cannot interact with surfactant molecules because of the electrostatic mismatching. Several research groups have reported mesostructured and mesoporous calcium phosphates prepared using surfactants. However the resultant products contained crystalline impurities such as brushite $\left(\mathrm{CaHPO}_{4} \cdot 2 \mathrm{HO}\right)$, monetite $\left(\mathrm{CaHPO}_{4}\right)$ and hydroxyapatite $\left(\mathrm{Ca}_{10}\left(\mathrm{PO}_{4}\right)_{6}(\mathrm{OH})_{2}\right)$ [19-30], and thus the surface areas of the mesoporous calcium phosphates were $90 \mathrm{~m}^{2} \mathrm{~g}$ at the largest [26].

In this study, we attempt to achieve the direct crystallization of mesoporous hydroxyapatite by chemical precipitation method using CTAB and P123 as structure-directing agents.

We succeeded in synthesizing a mesoporous hydroxyapatite with high surface area $\left(140 \mathrm{~m}^{2} / \mathrm{g}\right)$. HAp powders were synthesized using the micelle as a template system which was used as the surfactant. The effect of the surfactant on the BET specific average surface area of the particle was studied by 


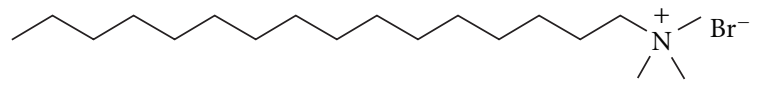

(a)

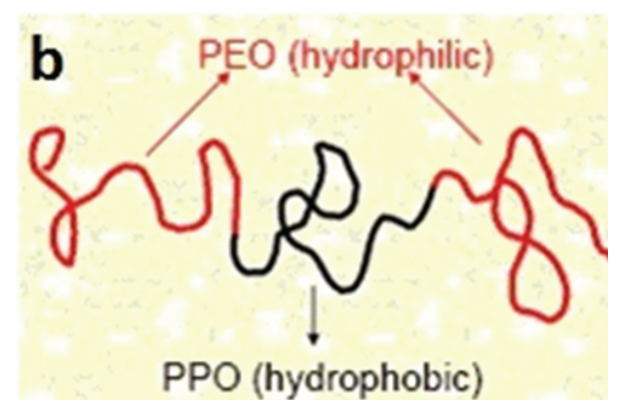

(b)

FIgure 1: The chemical structure of (a) CTAB (b) P123.

varying the P123 surfactant concentration as $0.01,0.02$, and $0.03 \mathrm{M}$.

\section{Experimental}

2.1. Materials and Procedure. Calcium chloride $\left(\mathrm{CaCl}_{2}\right.$, Merck co.), calcium hydroxide $\left(\mathrm{Ca}(\mathrm{OH})_{2}\right.$, Merck co.), and diammonium hydrogen phosphate $\left(\left(\mathrm{NH}_{4}\right)_{2} \mathrm{HPO}_{4}\right.$, Merck co.), phosphoric acid $\left(\mathrm{H}_{3} \mathrm{PO}_{4} 85 \%\right)$ were used as calcium and phosphorus sources, respectively.

CTAB and P123 as surfactant were used to synthesize nanoporous hydroxyapatite powders of this study. The chemical structures of P123 and CTAB are shown in Figure 1.

In a successful synthesis run to yield only single-phase $\left(\mathrm{Ca}_{10}\left(\mathrm{PO}_{4}\right)_{6}(\mathrm{OH})_{2}, \mathrm{HA}\right), 5.91 \mathrm{gr}$ diammonium hydrogen phosphate $\left(\left(\mathrm{NH}_{4}\right)_{2} \mathrm{HPO}_{4}\right)$ and 5 gr CTAB were dissolved in $70 \mathrm{~mL}$ deionized water at room temperature with stirring for $1 \mathrm{hr} \mathrm{pH}$ that was adjusted to 10 using sodium hydroxide. $8.21 \mathrm{gr}$ of $\mathrm{CaCl}_{2}$ was weighed into $75 \mathrm{~mL}$ of de-ionized water. Subsequently, the $\mathrm{CaCl}_{2}$ solution was added dropwise to the solution mixture, yielding a milky suspension, which was refluxed for $24 \mathrm{~h}$.

The precipitate was filtered and washed several times with distilled water to remove contaminated ions and surfactant. It was dried at $100^{\circ} \mathrm{C}$ for $24 \mathrm{~h}$. Calcination of powders was carried out at $400^{\circ} \mathrm{C}$ for $4 \mathrm{~h}$ to yield a white powder.

Nanoporous hydroxyapatite powders are also synthesized by using P123 as structure directing agent. Different amount of surfactant P123 was first dissolved in $50 \mathrm{gr}$ of deionized water with overnight stirring at room temperature. Calcium hydroxide $\mathrm{Ca}(\mathrm{OH})_{2}$ and phosphoric acid $\left(\mathrm{H}_{3} \mathrm{PO}_{4} 85 \%\right)$ were used as calcium and phosphorus sources, respectively.

Aqueous solutions of calcium and phosphorus precursors were prepared by dissolving $2.22 \mathrm{gr}$ of $\mathrm{Ca}(\mathrm{OH})_{2}$ and $1.764 \mathrm{gr}$ of $\mathrm{H}_{3} \mathrm{PO}_{4}$ into $10 \mathrm{~mL}$ of deionized water. The calcium and phosphorus precursor solutions were added into the surfactant solution which was refluxed for $24 \mathrm{~h}$.

The precipitate was filtered and washed several times with distilled water to remove contaminated ions and

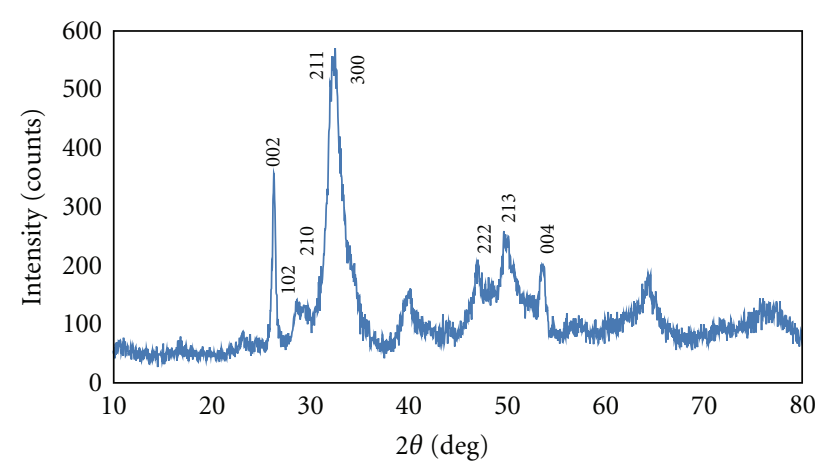

FIGURE 2: XRD pattern of as-dried nanoporous hydroxyapatite.

surfactant. It was dried at $100^{\circ} \mathrm{C}$ for $24 \mathrm{~h}$. Calcination of powders was carried out at $400^{\circ} \mathrm{C}$ for $4 \mathrm{~h}$ to yield a white powder.

2.2. Characterization. The X-ray powder diffraction patterns were recorded on a Philips 1830 diffractometer using $\mathrm{Cu} K \alpha$ radiation at $40 \mathrm{KV}$ and $40 \mathrm{~mA}$, with a $2 \theta$ step size of $0.02^{\circ}$ and a step time of $1 \mathrm{~s}$. Adsorption-desorption isotherms of the synthesized samples were measured at $77 \mathrm{~K}$ on micromeritics model ASAP 2010 sorptometer to determine an average pore diameter. Pore-size distributions were calculated by the Barrett-Joyner-Halenda (BJH) method, while surface area of the sample was measured by Brunaure-Emmet-Teller (BET) method. Before measurement, the samples were degassed at $160^{\circ} \mathrm{C}$ for at least $6 \mathrm{~h}$. The Fourier transform infrared spectra of samples were measured on a DIGILAB FTS 7000 instrument under attenuated total reflection (ATR) mode using a diamond module. TGA (Perkin-Elmer 7 series thermal analysis system) was used to determine the thermal behaviors of the synthesized hydroxyapatite. The measurements were performed at $10^{\circ} \mathrm{C} / \mathrm{min}$ from room temperature up to $800^{\circ} \mathrm{C}$ under the nitrogen flow of $20 \mathrm{~mL} / \mathrm{min}$.

\section{Results and Discussion}

Figure 2 shows the WAXRD patterns of the as-dried hydroxyapatite. WAXRD patterns of the nanoparticles consist of narrow peaks with $\mathrm{d}$ spacing consistent with well-ordered crystalline hydroxyapatite. It indicates that the sample consisted of a single phase of crystalline hydroxyapatite with a hexagonal structure (JCPDS 09-0432).

The XRD pattern demonstrates that pure and wellcrystalline HA is the only phase present.

The peaks within small angle range $\left(2\right.$ theta $\left.1-10^{\circ}\right)$ provide information on the arrangement presented by porous structure [26].

For LAXRD (Figure 3), the pattern of the as-dried samples shows a single intense diffraction peak at $2 \theta$ value of $1.46,1.33^{\circ}$ for samples synthesized in the presence of 3,15 , and $30 \mathrm{wt} \% \mathrm{P} 123$, respectively. The single peak suggested the presence of disordered mesoporous structure inside the sample, such as worm-like mesopores [26, 27]. 


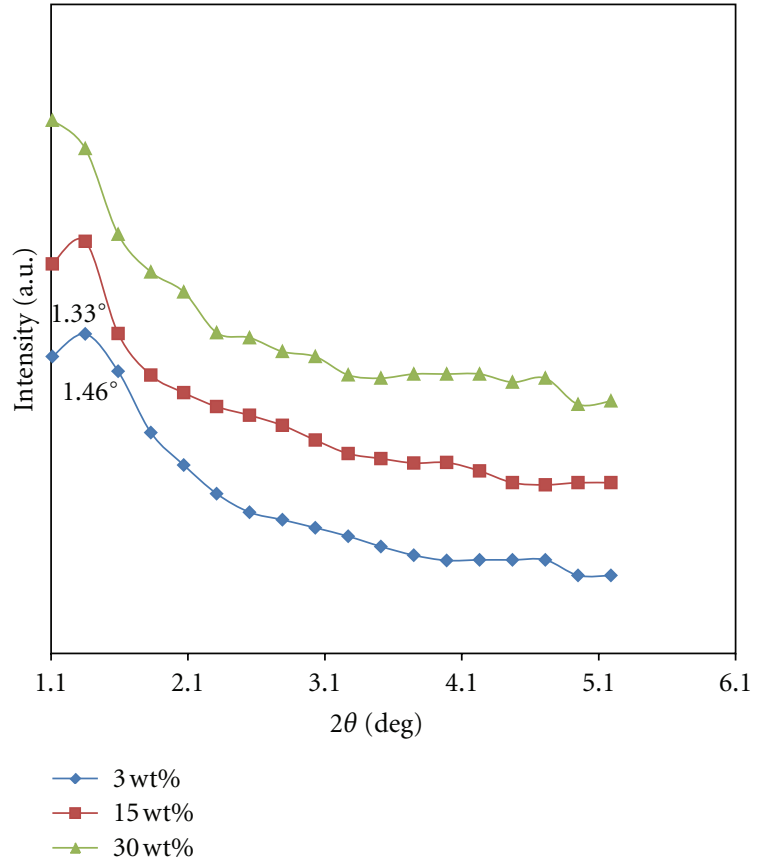

FIGURE 3: LAXRD pattern of as-prepared nanoporous hydroxyapatite using different P123 concentration.

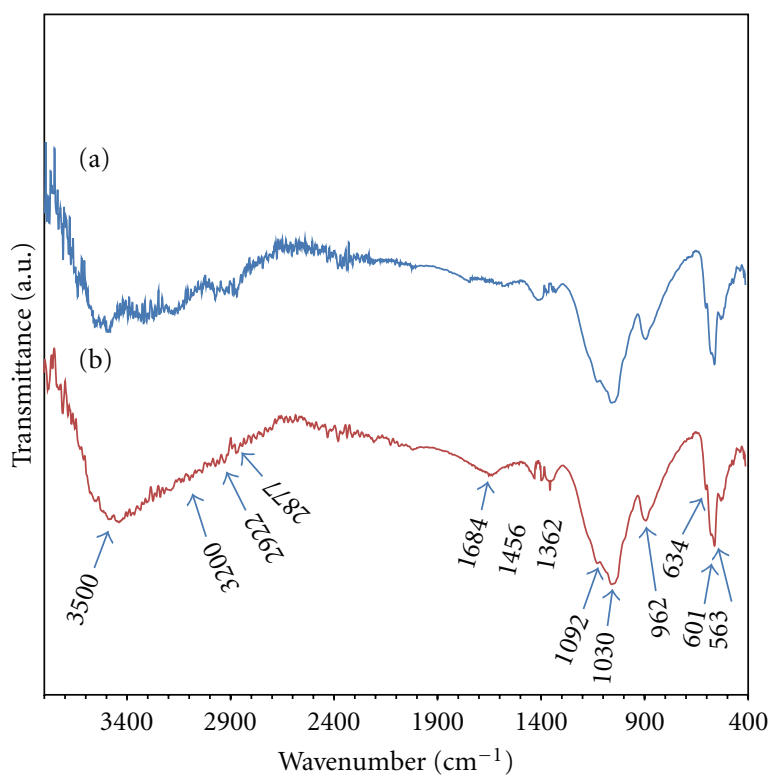

FIGURE 4: FTIR spectrum of as-prepared nanoporous hydroxyapatite using (a) P123 (b) CTAB.

It is believed that $d$ spacing in small angle range is corresponded to the distance between the neighboring pore centers, which can be regarded as the pore diameter while neglecting the wall thickness.

The FTIR spectra of nanoporous hydroxyapatite synthesized using P123 and CTAB as template are shown in Figure 4. For both samples, phosphate absorption bands occurred at ca. 1092, 1030, 962, 601, and $563 \mathrm{~cm}^{-1}$, and the hydroxide absorption bands at 3500 and $634 \mathrm{~cm}^{-1}$ were

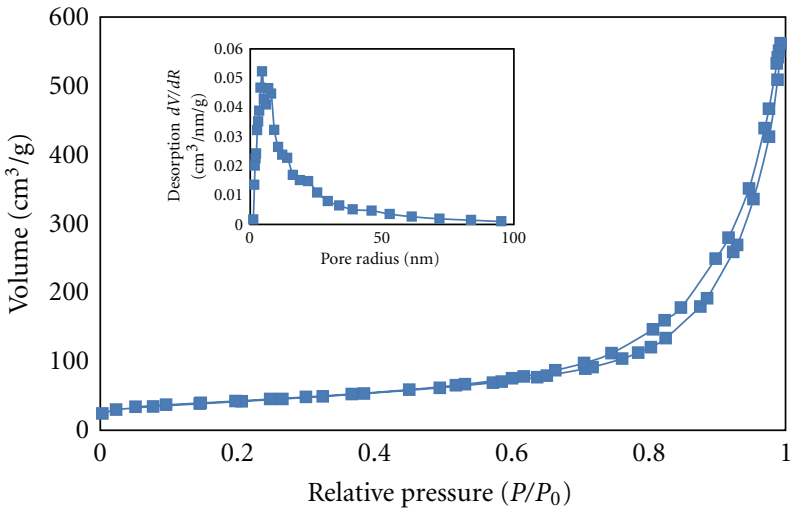

FIGURE 5: Nitrogen adsorption-desorption isotherms of nanoporous hydroxyapatite after calcination at $400^{\circ} \mathrm{C}$.

characteristic for a typical HAP FTIR spectrum. The bands at 2922 and $2877 \mathrm{~cm}^{-1}$ were ascribed to $\mathrm{CH}_{2}$ and $\mathrm{CH}$ groups, indicating the existence of surfactant chains within the HAP particles. The additional bands at 1684 and $1362 \mathrm{~cm}^{-1}$ were attributed to urea. The absorption band at $3200 \mathrm{~cm}^{-1}$ is due to adsorbed water.

Adsorption-desorption isotherms and pore size distributions of mesoporous hydroxyapatite calcined at $400^{\circ} \mathrm{C}$ are shown in Figure 5. Sample synthesized in the presence of $\mathrm{CTAB}$ exhibits a mesoporous materials type IV curve with a hysteresis loop. The BET surface area is calculated to be $147 \mathrm{~m}^{2} / \mathrm{g}$. The distribution of pore diameters was plotted according to the $\mathrm{BJH}$ nitrogen desorption. Figure 5 (insets) shows the distribution curves. Sharp peak appears at $46.5 \mathrm{~A}^{\circ}$ which means that pore diameters around $4.6 \mathrm{~nm}$ are in the majority.

Figures 6(a), 6(b), and 6(c) show the BET surface area in meter square per gram and the effect of various surfactant concentrations during synthesis on the final BET surface area of HAp particles. It was observed that a $30 \mathrm{wt} \% \mathrm{P} 123$ concentration gave the highest surface area in the final HAp powders, $50 \mathrm{~m}^{2} / \mathrm{g}$.

This resulting HAp precipitate interacts with the micelles to form a gel-like mass by electrostatic interaction. This leads to the formation of an organized structure, where the HAp precipitate is templated by micelles and solidified to form a matrix. During heat treatment, the micelle template decomposes into gases, such as $\mathrm{CO}_{2}$ and $\mathrm{HO}$, and leaves pores in the product. This type of mechanism is known in the silica-based inorganic system.

The surface area of the final powders is controlled by the particle size as well as the pore size and shape, which are determined by the micelle structure during powder preparation. In general, the micelle geometry is controlled by the concentration of the surfactant in solution and by the processing conditions. At different concentrations, the surfactant molecules aggregate into different forms, which influence the pore structure and surface area.

The thermal properties were studied by TGA in the temperature ranging from 25 to $800^{\circ} \mathrm{C}$ under nitrogen 


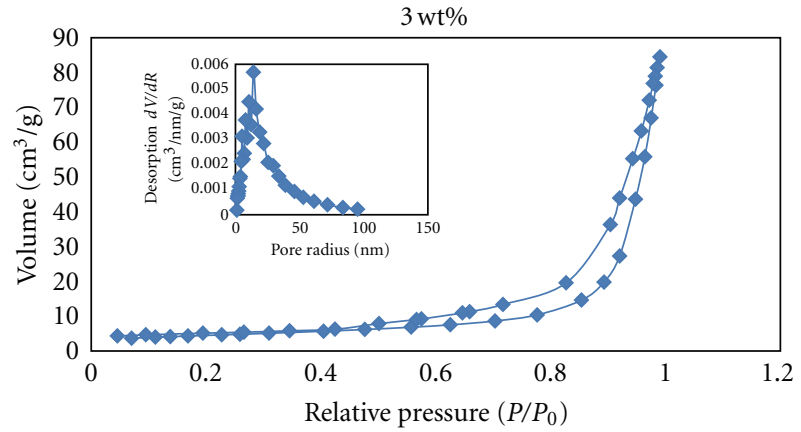

(a)

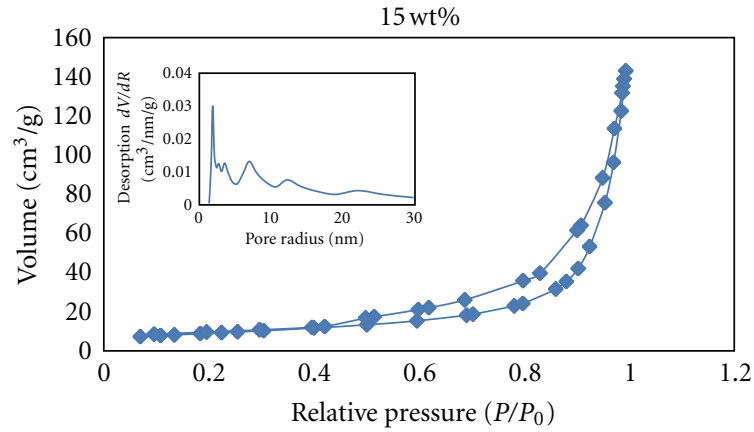

(b)

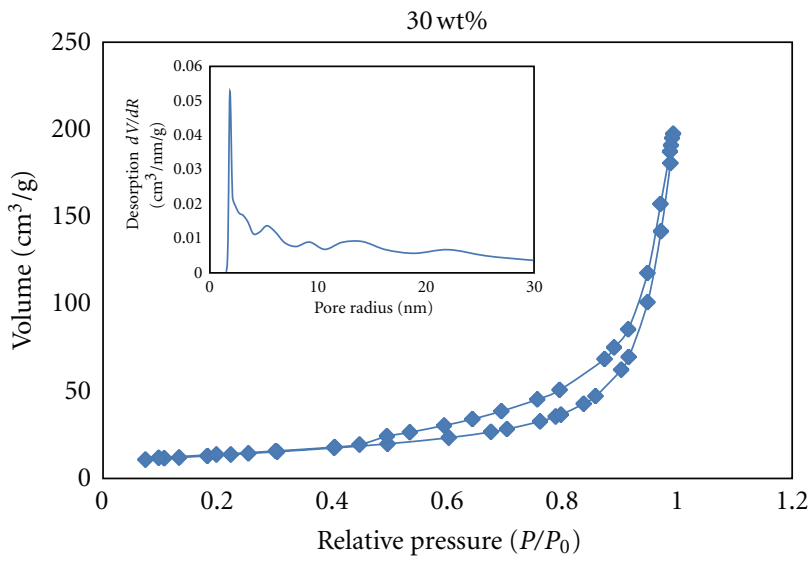

(c)

Figure 6: Adsorption-desorption isotherms of nanoporous hydroxyapatite after calcination at $400^{\circ} \mathrm{C}$ (a) $3 \mathrm{wt} \% \mathrm{P} 123$, (b) $15 \mathrm{wt} \% \mathrm{P} 123$, and (c) $30 \mathrm{wt} \% \mathrm{P} 123$.

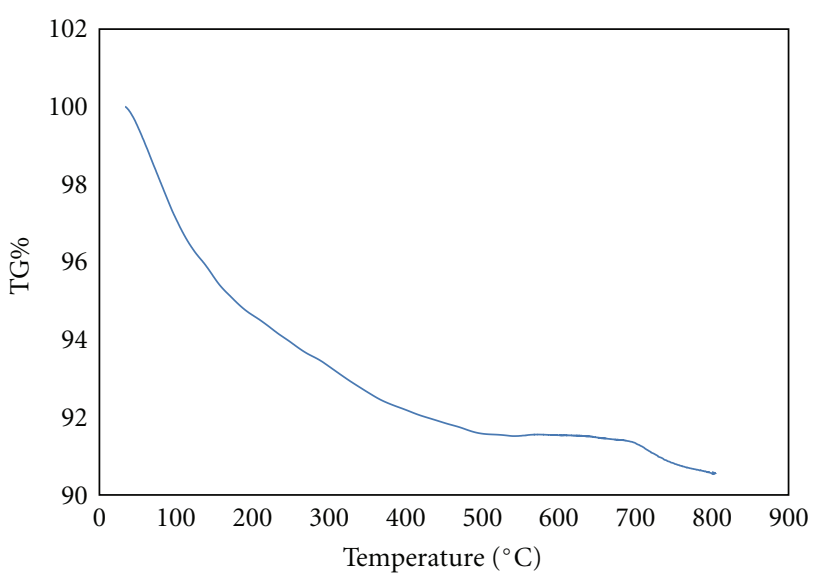

Figure 7: Thermal analysis for nanoporous hydroxyapatite using $\mathrm{CTAB}$ as template.

atmosphere, in order to choose precisely the calcinations temperature (Figure 5). The TGA curves of nanoporous hydroxyapatite synthesized by using CTAB (Figure 7) and synthesized by using P123 (Figure 8 ) show continuing weight losses from room temperature to $200^{\circ} \mathrm{C}$ and also a sharp weight loss between 350 and $450^{\circ} \mathrm{C}$, approximating $1 \%$

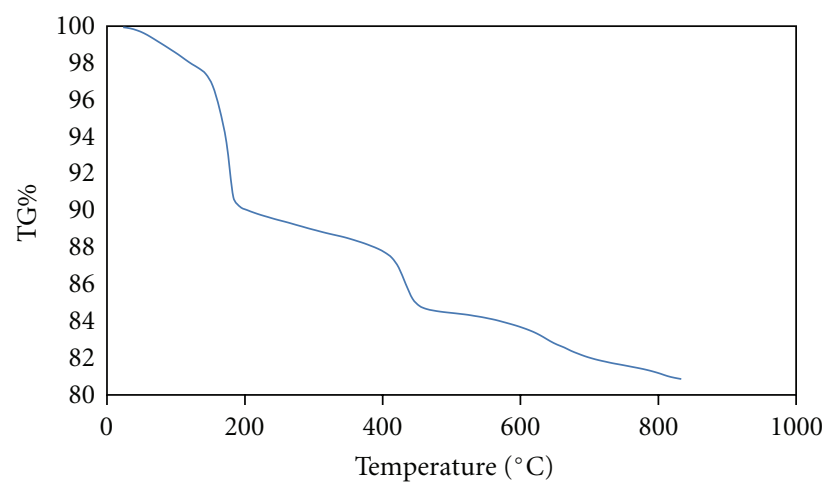

FIGURE 8: Thermal analysis for nanoporous hydroxyapatite using P123 as template.

and $4 \mathrm{wt} \%$ of the sample synthesized in the presence of CTAB and 10.3 and $3.7 \mathrm{wt} \%$ of the sample synthesized in the presence of $\mathrm{P} 123$. The weight change below $200^{\circ} \mathrm{C}$ can be attributed to the loss of adsorbed water and sample drying. The weight loss in the range of $350-450^{\circ} \mathrm{C}$ can be ascribed to the decomposition and release of organic groups. FTIR spectrum of hydroxyapatite after calcination at $800^{\circ} \mathrm{C}$ (Figure 9) confirms the release of organic groups. 


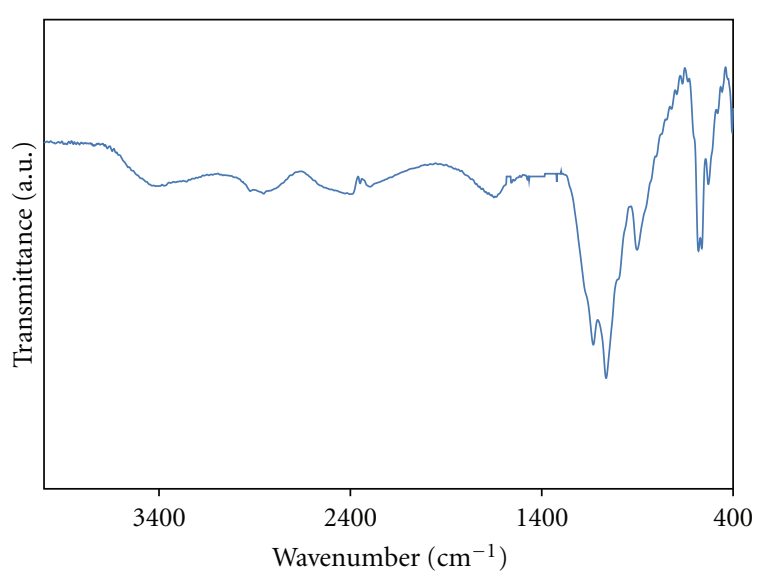

FIGURE 9: FTIR spectrum of hydroxyapatite after calcination at $800^{\circ} \mathrm{C}$.

\section{Conclusions}

We have demonstrated the synthesis of phase-pure nanoporous hydroxyapatite inorganic using the P123 and CTAB micelle systems, where the nonionic surfactant concentration was found to have an influence on nanoparticle surface area. At the $30 \mathrm{wt} \%$ P123 surfactant concentration, HAp particles showed the highest surface area $50 \mathrm{~m}^{2} / \mathrm{g}$. By using cationic surfactant CTAB, surface area increased to $147 \mathrm{~m}^{2} / \mathrm{g}$.

\section{Acknowledgment}

Research council of Iran University of Science and Technology (IUST, Iran) is appreciated for the financial support.

\section{References}

[1] S. V. Dorozhkin and M. Epple, "Biological and medical significance of calcium phosphates," Angewandte Chemie-International Edition, vol. 41, no. 17, pp. 3130-3146, 2002.

[2] J. Currey, "Biomaterials: sacrificial bonds heal bone," Nature, vol. 414, no. 6865, article 699, 2001.

[3] J. B. Thompson, J. H. Kindt, B. Drake, H. G. Hansma, D. E. Morse, and P. K. Hansma, "Bone indentation recovery time correlates with bond reforming time," Nature, vol. 414, no. 6865, pp. 773-776, 2001.

[4] Y. Yamashita, A. Uchida, T. Yamakawa, Y. Shinto, N. Araki, and K. Kato, "Treatment of chronic osteomyelitis using calcium hydroxyapatite ceramic implants impregnated with antibiotic," International Orthopaedics, vol. 22, no. 4, pp. 247-251, 1998.

[5] W. Paul and C. P. Sharma, "Development of porous spherical hydroxyapatite granules: application towards protein delivery," Journal of Materials Science, vol. 10, no. 7, pp. 383-388, 1999.

[6] S. Sebti, R. Tahir, R. Nazih, A. Saber, and S. Boulaajaj, "Hydroxyapatite as a new solid support for the Knoevenagel reaction in heterogeneous media without solvent," Applied Catalysis A, vol. 228, no. 1-2, pp. 155-159, 2002.

[7] C. T. Kresge, M. E. Leonowicz, W. J. Roth, J. C. Vartuli, and J. S. Beck, "Ordered mesoporous molecular sieves synthesized by a liquid-crystal template mechanism," Nature, vol. 359, no. 6397, pp. 710-712, 1992.
[8] J. S. Beck, J. C. Vartuli, W. J. Roth et al., "A new family of mesoporous molecular sieves prepared with liquid crystal templates," Journal of the American Chemical Society, vol. 114, no. 27, pp. 10834-10843, 1992.

[9] D. Zhao, J. Feng, Q. Huo et al., "Triblock copolymer syntheses of mesoporous silica with periodic 50 to 300 angstrom pores," Science, vol. 279, no. 5350, pp. 548-552, 1998.

[10] X. S. Zhao, G. Q. Lu, and G. J. Millar, "Advances in mesoporous molecular sieve MCM-41," Industrial and Engineering Chemistry Research, vol. 35, no. 7, pp. 2075-2090, 1996.

[11] P. Selvam, S. K. Bhatia, and C. G. Sonwane, "Recent advances in processing and characterization of periodic mesoporous MCM-41 silicate molecular sieves," Industrial and Engineering Chemistry Research, vol. 40, no. 15, pp. 3237-3261, 2001.

[12] A. Sayari, "Catalysis by crystalline mesoporous molecular sieves," Chemistry of Materials, vol. 8, no. 8, pp. 1840-1852, 1996.

[13] A. Corma, "From microporous to mesoporous molecular sieve materials and their use in catalysis," Chemical Reviews, vol. 97, no. 6, pp. 2373-2419, 1997.

[14] A. Taguchi and F. Schüth, "Ordered mesoporous materials in catalysis," Microporous and Mesoporous Materials, vol. 77, no. 1, pp. 1-45, 2005.

[15] F. Schüth, "Endo- and exotemplating to create high-surfacearea inorganic materials," Angewandte Chemie-International Edition, vol. 42, no. 31, pp. 3604-3622, 2003.

[16] M. Anbia and S. E. Moradi, "Adsorption of naphthalenederived compounds from water by chemically oxidized nanoporous carbon," Chemical Engineering Journal, vol. 148, no. 23, pp. 452-458, 2009.

[17] M. Anbia and A. Ghaffari, "Adsorption of phenolic compounds from aqueous solutions using carbon nanoporous adsorbent coated with polymer," Applied Surface Science, vol. 255, no. 23, pp. 9487-9492, 2009.

[18] M. Anbia and N. Mohammadi, "A nanoporous adsorbent for removal of furfural from aqueous solutions," Desalination, vol. 249, no. 1, pp. 150-153, 2009.

[19] G. A. Ozin, N. Varaksa, N. Coombs, J. E. Davies, D. D. Perovic, and M. Ziliox, "Bone mimetics: a composite of hydroxyapatite and calcium dodecylphosphate lamellar phase," Journal of Materials Chemistry, vol. 7, no. 8, pp. 1601-1607, 1997.

[20] I. Soten and G. A. Ozin, "Porous hydroxyapatite-dodecylphosphate composite film on titania- titanium substrate," Journal of Materials Chemistry, vol. 9, no. 3, pp. 703-710, 1999.

[21] Z. Y. Yuan, J. Q. Liu, L. M. Peng, and B. L. Su, "Morphosynthesis of vesicular mesostructured calcium phosphate under electron irradiation," Langmuir, vol. 18, no. 6, pp. 2450-2452, 2002.

[22] J. Yao, W. Tjandra, Y. Z. Chen K, K. C. Tam, J. Ma, and B. Soh, "Hydroxyapatite nanostructure material derived using cationic surfactant as a template," Journal of Materials Chemistry, vol. 13, no. 12, pp. 3053-3057, 2003.

[23] B. Prélot and T. Zemb, "Calcium phosphate precipitation in catanionic templates," Materials Science and Engineering $C$, vol. 25, no. 5-8, pp. 553-559, 2005.

[24] S. Sadasivan, D. Khushalani, and S. Mann, "Synthesis of calcium phosphate nanofilaments in reverse micelles," Chemistry of Materials, vol. 17, no. 10, pp. 2765-2770, 2005.

[25] Y. F. Zhao and J. Ma, "Triblock co-polymer templating synthesis of mesostructured hydroxyapatite," Microporous and Mesoporous Materials, vol. 87, no. 2, pp. 110-117, 2005.

[26] S. M. Schmidt, J. McDonald, E. T. Pineda et al., "Surfactant based assembly of mesoporous patterned calcium phosphate 
micron-sized rods," Microporous and Mesoporous Materials, vol. 94, no. 1-3, pp. 330-338, 2006.

[27] Y. Tokuoka, Y. Ito, K. Kitahara, Y. Niikura, A. Ochiai, and N. Kawashima, "Preparation of monetite $\left(\mathrm{CaHPO}_{4}\right)$ with hexagonally packed mesoporous structure by a sol-gel method using cationic surfactant aggregates as a template," Chemistry Letters, vol. 35, no. 11, pp. 1220-1221, 2006.

[28] C. Liu, X. Ji, and G. Cheng, "Template synthesis and characterization of highly ordered lamellar hydroxyapatite," Applied Surface Science, vol. 253, no. 16, pp. 6840-6843, 2007.

[29] J. Fan, J. Lei, C. Yu, B. Tu, and D. Zhao, "Hard-templating synthesis of a novel rod-like nanoporous calcium phosphate bioceramics and their capacity as antibiotic carriers," Materials Chemistry and Physics, vol. 103, no. 2-3, pp. 489-493, 2007.

[30] J. Zhang, M. Fujiwara, Q. Xu, Y. Zhu, M. Iwasa, and D. Jiang, "Synthesis of mesoporous calcium phosphate using hybrid templates," Microporous and Mesoporous Materials, vol. 111, no. 1-3, pp. 411-416, 2008. 

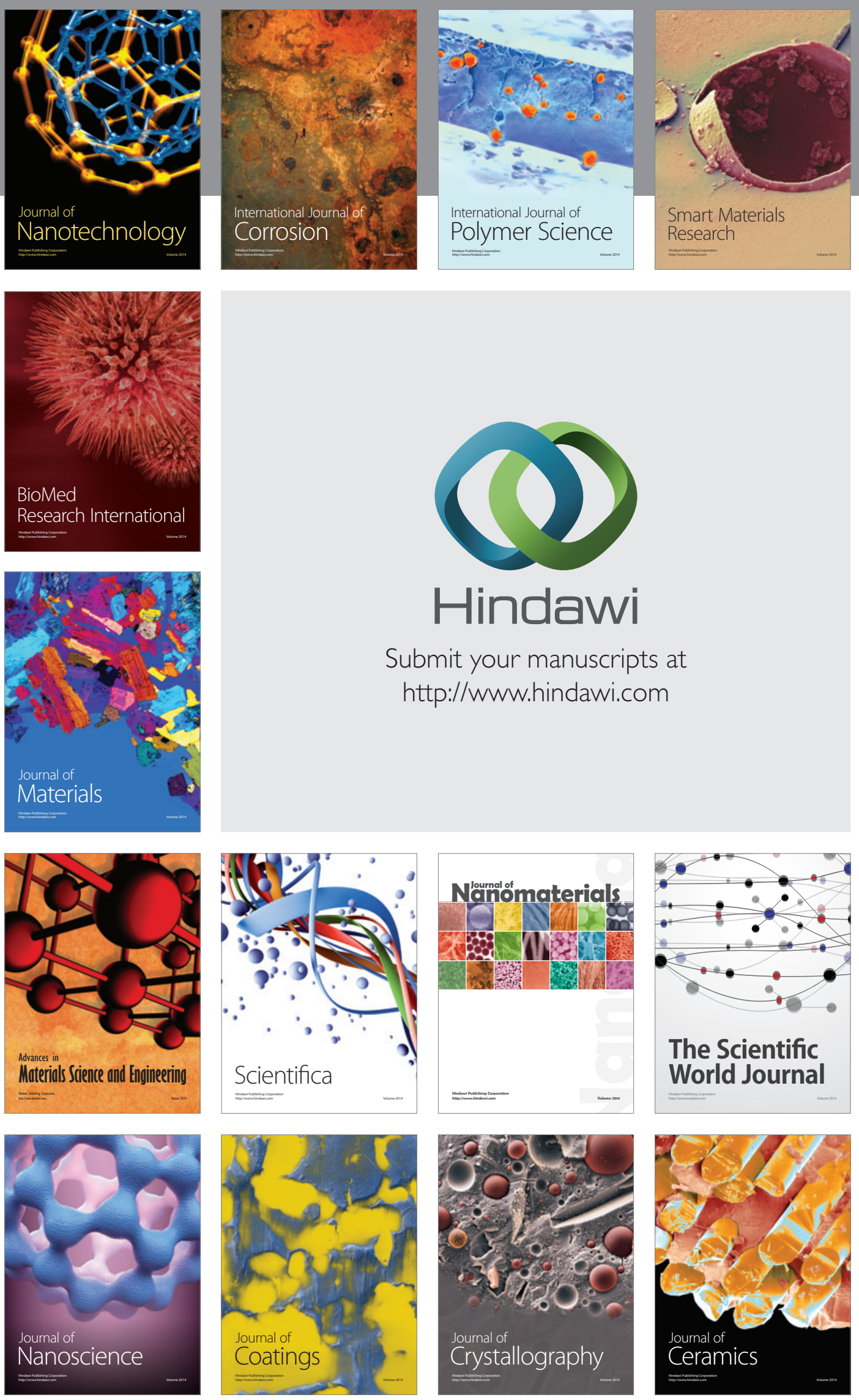

The Scientific World Journal

Submit your manuscripts at

http://www.hindawi.com

\section{World Journal}

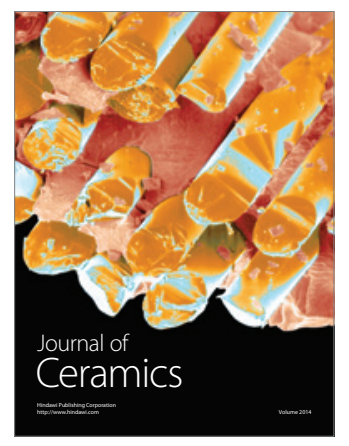

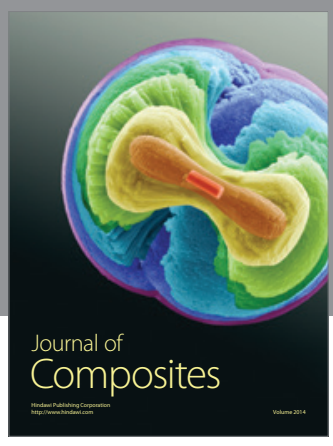
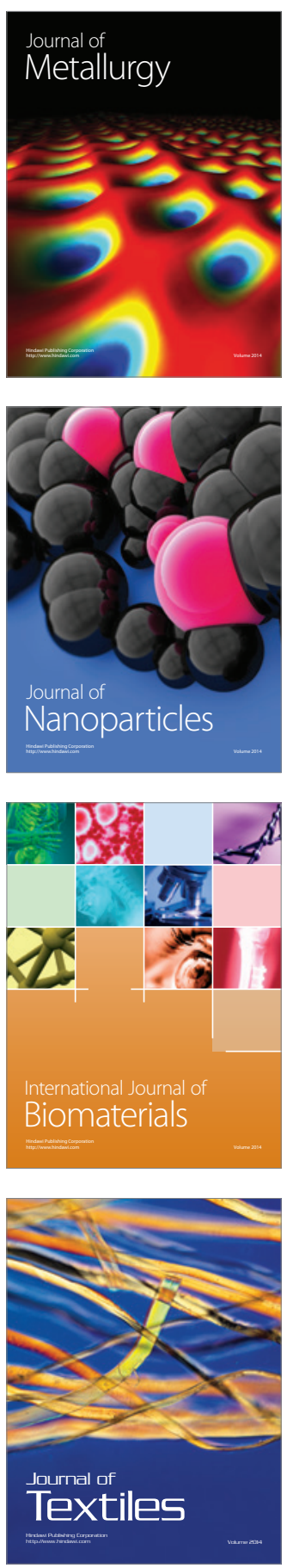